1 Noel GL, Suh HK, Franz AG. Prolactin release during nursing and breast stimulation in postpartum and non-postpartum subjects. f Clin Endocrinol Metab 1974;38:413-23.

12 Tyson JE, Khojandi M, Huth J, Andreassen B. Influence of prolactin secretion on human lactation. $\mathcal{F}$ Clin Endocrinol Metab 1975;40:764-73.

13 Tucker HA. Endocrinology of lactation. Semin Perinatol 1979;3:199-223.

14 Lunn PG, Prentice MA, Austin S, Whitehead RG. Influence of maternal diet on plasma-prolactin during lactation. Lancet 1980;i:623-5.

15 Tyson JE, Perez A, Zanarty J. Human lactational response to oral thyrotropin releasing hormone. 7 Clin Endocrinol Metab 1976;43:760-8.

16 Ylikorkala O, Kivinen S, Kauppila A. Oral administration of TRH in puerperal women: effect on insufficient lactation, thyroid hormones and the responses of TSH and prolactin to intravenous TRH. Acta Encrinol (Copenh) 1980;93:413-8.

${ }^{17}$ Ruis H, Holland R, Doesburg W, Broeders G, Corbey R. Oxytocin enhances onset of lactation among mothers delivering prematurely. Br Med f 1981;283:340-2.

18 Aono T, Shioji T, Aki T, Hirota K, Nomura A, Kurachi K. Augmentation of puerperal lactation by oral administration of sulpiride. $\mathcal{F}$ Clin Endocrinol Metab 1979;48:478-82.

\title{
Response of patients to upper gastrointestinal endoscopy: effect of inherent personality traits and premedication with diazepam
}

\author{
M J WEBBERLEY, A CUSCHIERI
}

\begin{abstract}
The influence of personality traits on the reaction of patients to upper gastrointestinal endoscopy was studied prospectively in 86 patients. High $N$ (neuroticism) scores on the Eysenck personality inventory were associated with poor tolerance to and future compliance with the procedure. Although premedication with diazepam did not affect the degree of discomfort and distress during the procedure, it guaranteed acceptance of repeat endoscopy by virtue of its strong amnesic effect. By contrast, not giving premedication to patients who were anxious and had high $N$ scores jeopardised future compliance.

These findings suggest that a version of the Eysenck personality inventory should be used to assess patients' neurotic phenotype and their need for premedication before endoscopy. Alternatively, all patients might be given premedication.
\end{abstract}

\section{Introduction}

Considerable controversy exists regarding the benefit of premedication with diazepam in patients undergoing fibreoptic upper gastrointestinal endoscopy, ${ }^{1-3}$ but most studies have neglected the influence of personality traits on the patients' reaction to endoscopy despite the prevalent clinical impression that neurotic individuals exhibit poor compliance to this investigative procedure. The use of diazepam seems justified by its powerful anxiolytic and amnesic effects. On the other hand, there are well-documented disadvantages to its use, including its long half life in the circulation, inducement of violence in young alcoholics, respiratory depression, and thrombophlebitis due to a local irritant effect at the site of injection, although this last has been reduced considerably by use of a combination of diazepam and intralipid (Diazemuls). These adverse effects have precluded its use by some endoscopists particularly when the procedure is performed on outpatients. The aim of this study was to evaluate any influence of inherent personality traits on

\footnotetext{
Department of Surgery, Ninewells Hospital and Medical School, Dundee DD1 9SY

M J WEBBERLEY, final-year medical student

A CUSCHIERI, MD, CHM, professor
}

patient reaction to endoscopy with and without diazepam with a view to improving overall patient compliance.

\section{Patients and methods}

The study was undertaken prospectively on 86 patients ( 38 women, $48 \mathrm{men}$ ) selected at random and about to undergo upper gastrointestinal endoscopy in a clinical measurement unit served by several endoscopists (physicians and surgeons). The patients were aged 16-85 years; 77 were outpatients and nine inpatients.

The nature of the forthcoming procedure was explained to each patient by a nurse. Thereafter each patient was asked to complete the Eysenck personality inventory ${ }^{4}$ and to indicate his degree of anxiety on a linear anxiety scale. The Eysenck personality inventory is used to assess the phenotype of patients' personality traits and is well validated. It contains three scales: $\mathrm{N}$ measures degrees of neuroticism, $\mathrm{E}$ measures extraversion or introversion, and $\mathrm{L}$ denotes the lie scale, which indicates whether an individual is faking his responses. A high $\mathrm{L}$ score should lead the examiner to regard the $\mathrm{N}$ and $\mathrm{E}$ scores with scepticism.

After completing the inventory each patient was conducted to the endoscopy room. Patients received intravenous diazepam (10 to 20 $\mathrm{mg}$ ) and atropine or no sedation or premedication in accordance with the practice of the endoscopist, some of whom administered diazepam routinely to all their patients and others not. We did not actively interfere in the procedure. Fifty-nine of the 86 patients were given diazepam. All patients were examined in the left lateral position in an illuminated room with an Olympus paediatric fibreoptic endoscope.

Observer assessment during endoscopy was aimed at noting the patients' tolerance to the procedure, co-operation, anxiety, and reaction to insertion of the endoscope and air insufflation. All patients were interviewed briefly on recovery and asked to complete a questionnaire about their impressions of and feelings on the procedure and more specifically their memory of the procedure, their attitude towards it, and their willingness to undergo further endoscopy if necessary. A further questionnaire was sent to each patient one to two weeks after endoscopy; this covered the same points, albeit in more detail, and was intended to assess whether patients' delayed impressions differed from their reactions immediately after endoscopy. Statistical analyses were carried out using Student's $t$ test for unpaired data and the $\chi^{2}$ test as appropriate.

\section{Results}

Anxiety-The patients were subgrouped according to whether they were very anxious, moderately anxious, or not anxious before the procedure (table I). The very anxious subgroup had a marginally higher mean $\mathrm{N}$ score than the rest, but this difference was not significant $(0.5>p>0.01)$. Anxiety before the procedure did not significantly alter tolerance to it $(p>0.5)$. 
Tolerance to procedure-There was no significant difference in the proportions of patients who could not tolerate the procedure between those who received diazepam (11/59) and those who did not $(6 / 27)$. Patients who did not receive premedication and could not tolerate the procedure, however, had significantly higher $\mathrm{N}$ scores than the rest (table II).

Memory of the procedure-Amnesia (total in 24 patients and partial in 20) was observed only in patients given diazepam; this effect of diazepam on loss of memory of the endoscopy was significant

\begin{tabular}{lcc}
$\begin{array}{l}\text { TABLE I-Anxiety } \\
\text { procedure }\end{array}$ & and mean $\pm S D$ & $N$ scores before \\
\hline & $\mathrm{n}$ & N score \\
\hline Very anxious & 15 & $14 \cdot 13 \pm 4 \cdot 63$ \\
Moderately anxious & 25 & $12 \cdot 28 \pm 4 \cdot 34$ \\
Not anxious & 46 & $11 \cdot 17 \pm 4 \cdot 84$
\end{tabular}

TABLE II-Tolerance and mean $\pm S D N$ scores

\begin{tabular}{lrc}
\hline & $\mathrm{n}$ & $\mathrm{N}$ score \\
\hline Procedure tolerated & 69 & $11 \cdot 42 \pm 4 \cdot 74$ \\
Procedure not tolerated & 17 & $13 \cdot 64 \pm 5 \cdot 42$ \\
Patients given diazepam & 11 & $13 \cdot 27 \pm 5 \cdot 69$ \\
Patients not given diazepam & 6 & $16 \cdot 0 \pm 3 \cdot 09^{*}$ \\
\hline${ }^{*} 0.05>\mathrm{p}>0.02$. & &
\end{tabular}

TABLE III-Patient reaction and mean $\pm S D N$ scores

\begin{tabular}{lcc}
\hline Reaction to procedure & $\mathrm{n}$ & $\mathrm{N}$ score \\
\hline Strongly disliked & 14 & $14 \cdot 5 \pm 4 \cdot 2^{*}$ \\
Indifferent & 7 & $10 \cdot 86 \pm 5 \cdot 24$ \\
Disliked, but not strongly & 65 & $11 \cdot 48 \pm 3.89$ \\
\hline$*^{*} 0.01>\mathrm{p}>0.001$. & &
\end{tabular}

TABLE IV-Willingness to undergo procedure again and mean $\pm S D N$ scores

\begin{tabular}{|c|c|c|}
\hline & $\mathrm{n}$ & $\mathrm{N}$ score \\
\hline Would accept immediately & 69 & $11 \cdot 0 \pm 4 \cdot 90$ \\
\hline Would accept anxiously & 13 & $14 \cdot 0 \pm 4 \cdot 31\} * *$ \\
\hline Would refuse completely & 4 & $\left.17 \cdot 0 \pm 2.58^{*}\right\}^{* *}$ \\
\hline
\end{tabular}

$* 0.05>\mathrm{p}>0.02$
$* * 0.01>\mathrm{p}>0.001$

TABLE $\mathrm{v}-$ Comparison of immediate and late impressions of procedure (figures are percentages)

\begin{tabular}{|c|c|c|}
\hline & $\begin{array}{c}\text { Early } \\
\text { questionnaire }\end{array}$ & $\begin{array}{c}\text { Late } \\
\text { questionnaire }\end{array}$ \\
\hline \multicolumn{3}{|c|}{ Willingness to undergo procedure again } \\
\hline Would refuse completely & $4 \cdot 6$ & \\
\hline Would accept immediately & 80 & 73 \\
\hline Would accept anxiously & 15 & 20 \\
\hline \multicolumn{3}{|c|}{ Strong dislike of procedure } \\
\hline Yes & & 18 \\
\hline & & 66 \\
\hline Indifferent & 9 & 15 \\
\hline
\end{tabular}

$(p=0.001)$. There was no correlation between $\mathrm{N}$ scores and memory of the procedure.

Reaction after endoscopy-Fourteen patients disliked the procedure strongly (two given diazepam and 12 not given diazepam). This difference was significant $(\mathrm{p}<0 \cdot 001)$. The $\mathrm{N}$ score of these 14 patients was significantly higher than that of the rest (table III).

Willingness to undergo repeat endoscopy-Four patients, who had not received diazepam, said that they would refuse completely a second endoscopy; 13 said that they would accept anxiously, of whom eight had not received diazepam. This effect of diazepam on future compliance was significant $(p<0.001)$. Table IV shows the relation between future compliance and $\mathrm{N}$ scores. Significantly higher $\mathbf{N}$ scores were obtained from patients who said that they would refuse completely a second endoscopy or accept it anxiously.

Subsequent reaction to procedure-Comparison of immediate and late impressions of the procedure (table $\mathrm{V}$ ) indicated that patients did not significantly alter their views during the study period but tended to develop a less favourable attitude towards the procedure.

Effect of long-term diazepam-Nine of the patients studied were receiving long-term diazepam treatment. All but one received $\mathbb{D}$ diazepam before their endoscopy. None of them said that they would refuse a further endoscopy but four said that they would be anxious about it. Their mean $\mathrm{N}$ score $(16 \cdot 125 \pm 3 \cdot 722)$ was significantly higher $\frac{\varrho}{\bar{F}}$ than that of the rest of the patients in the study.

\section{Discussion}

The use of diazepam for premedication is controversial, some $\overrightarrow{\bar{S}}$ workers reporting an improved tolerance of the procedure after $-\overrightarrow{0}$ its use ${ }^{12}$ and others maintaining that sedation for endoscopy is $\frac{C}{\sigma}$ required only exceptionally. ${ }^{3}$ In this study we observed that, $\overline{\bar{m}}$ though tolerance did not differ significantly between those $\mathbb{\Phi}$ patients given diazepam and those not, a significantly higher proportion of patients not given diazepam strongly disliked the $\omega$ procedure and would be poorly compliant for future endoscopies. $\overrightarrow{0}$ The $N$ (neuroticism) scores of these patients were significantly $\overrightarrow{.}$ higher than those of the rest. Only one patient in the study had $\vec{\sigma}$ a high L score (41), and no correlation was found between $\mathrm{E}$ scores and reaction to endoscopy.

There have been few studies on the effect of psychological i variables on patients' reactions to endoscopy. In one study ${ }^{5}$ psychological preparation of patients for endoscopy by giving a detailed technical description of the forthcoming procedure was $\omega_{-}$ found to be beneficial. The patients required less sedation and $\mathcal{G}$ their overall tolerance was better. Other studies suggest that an environment that will help the patient relax should be created, ${ }^{6}$ 은 with dimmed lighting and vocal and tactical encouragement $N$ during the procedure. In general the results of the present study show that patients who did not tolerate the procedure, those who were anxious beforehand, and those who developed $\vec{\theta}$ unfavourable attitudes to upper gastrointestinal endoscopy had $\infty$ higher $\mathrm{N}$ scores on the Eysenck personality inventory than ${ }^{N}$ patients who did not object to the examination. If these intolerant patients are not given premedication with diazepam their compliance with future advice on the need for subsequent $\overline{0}$ endoscopy is jeopardised.

The main benefit of diazepam in the group of patients who do not tolerate the procedure is related to its amnesic effect; it $\overrightarrow{\vec{O}}$ does not materially influence tolerance and comfort during 3 endoscopy itself. Review of patients with high $\mathrm{N}$ scores including three young teenage girls showed that, while they tolerated the endoscopy extremely badly, none would refuse a subsequent endoscopy. In practice a modified version of the Eysenck personality inventory to assess the $\mathrm{N}$ scores, taking two to three minutes to complete, would be sufficient to assess the neurotic 3 phenotype and indicate the absolute need for premedication 8 before endoscopy. The alternative would be to premedicate all patients before the procedure.

We thank Dr Barbara Ballinger, of the department of psychiatry, $N$ Ninewells Hospital and Medical School, Dundee, for her help and $\rightarrow$ advice and the dean of the faculty of medicine, Dundee University, for financial help to MJW.

\section{References}

1 Hoare AM, Hawkins CF. Upper gastrointestinal endoscopy with and $\frac{0}{\frac{C}{C}}$ without sedation. Patients' opinions. $B r \operatorname{Med} \mathcal{F} 1976$;ii:20.

2 Castiglioni LJ, Allen TS, Patterson M. Intravenous diazepam: an improvement in pre-endoscopic medication. Gastrointest Endosc 1973; T 19:134-6.

3 Petersen H, Myren J. Premedication for peroral endoscopy. Two double- $\overparen{\mathbb{D}}$ blind studies. Scand f Gastroenterol 1972;7:583-7.

4 Eysenck T, Eysenck SBG. Manual of the Eysenck personality inventory. 을 London: Hodder and Stoughton: 1963.

5 Johnson JE, Morrissey JF, Leventhal H. Psychological preparation for an endoscopic examination. Gastrointest Endosc 1973;19:180-2.

${ }^{6}$ Hofkin GA. Simplified anaesthesia for peroral endoscopy. Gastrointest Endosc 1973;16:38-9.

(Accepted 24 May 1982) 